\title{
Comparisons of simulation results between passive and active fluid structure interaction models for left ventricle in hypertrophic obstructive cardiomyopathy
}

Xueying Huang ${ }^{1,2^{*}}$, Long Deng ${ }^{3 \dagger}$, Heng Zuo ${ }^{4}$, Chun Yang ${ }^{2,5}$, Yunhu Song ${ }^{3}$, Mary Lesperance ${ }^{6}$ and Dalin Tang ${ }^{2,7}$

${ }^{*}$ Correspondence:

xhuang@xmu.edu.cn

${ }^{\dagger}$ Xueying Huang and Long

Deng contributed equally to

this work

${ }^{1}$ School of Mathematical

Sciences, Xiamen University, Xiamen 361005, Fujian, China Full list of author information is available at the end of the article

\begin{abstract}
Background: Patient-specific active fluid-structure interactions (FSI) model is a useful approach to non-invasively investigate the hemodynamics in the heart. However, it takes a lot of effort to obtain the proper external force boundary conditions for active models, which heavily restrained the time-sensitive clinical applications of active computational models.
\end{abstract}

Methods: The simulation results of 12 passive FSI models based on 6 patients' preoperative and post-operative CT images were compared with corresponding active models to investigate the differences in hemodynamics and cardiac mechanics between these models.

Results: In comparing the passive and active models, it was found that there was no significant difference in pressure difference and shear stress on mitral valve leaflet (MVL) at the pre-SAM time point, but a significant difference was found in wall stress on the inner boundary of left ventricle (endocardium). It was also found that pressure difference on the coapted MVL and the shear stress on MVL were significantly decreased after successful surgery in both active and passive models.

Conclusion: Our results suggested that the passive models may provide good approximated hemodynamic results at 5\% RR interval, which is crucial for analyzing the initiation of systolic anterior motion (SAM). Comparing to active models, the passive models decrease the complexity of the modeling construction and the difficulty of convergence significantly. These findings suggest that, with proper boundary conditions and sufficient clinical data, the passive computational model may be a good substitution model for the active model to perform hemodynamic analysis of the initiation of SAM.

Keywords: Fluid-structure interactions, Left ventricle, Mitral valve, Systolic anterior motion, Passive computational model, Active computational model

(c) The Author(s) 2021. This article is licensed under a Creative Commons Attribution 4.0 International License, which permits use, sharing, adaptation, distribution and reproduction in any medium or format, as long as you give appropriate credit to the original author(s) and the source, provide a link to the Creative Commons licence, and indicate if changes were made. The images or other third party material in this article are included in the article's Creative Commons licence, unless indicated otherwise in a credit line to the material. If material is not included in the article's Creative Commons licence and your intended use is not permitted by statutory regulation or exceeds the permitted use, you will need to obtain permission directly from the copyright holder. To view a copy of this licence, visit http://creativecommons.org/ licenses/by/4.0/. The Creative Commons Public Domain Dedication waiver (http://creativecommons.org/publicdomain/zero/1.0/) applies to the data made available in this article, unless otherwise stated in a credit line to the data. 


\section{Background}

Hypertrophic obstructive cardiomyopathy (HOCM) is characterized by hypertrophic myocardium and obstruction in the left ventricular outflow. Patients with this disease might suffer from severe heart failure and even sudden death. Septal myectomy is the golden standard treatment for the symptomatic patients [1, 2]. However, this is a very challenging procedure as the extent of myectomy is very difficult to be determined. This is because that inadequate excision cannot abolish left ventricular outflow obstruction, while the excessive myectomy might produce ventricular septal defect or irregular heart rhythms, such as complete heart block. Therefore, a non-invasive method for helping surgeons make the optimal design of the surgery is significantly required.

Several heart models, such as structural finite element models, computational fluid dynamics models, fluid-structure interactions (FSI) models, multi-patient models, have been proposed in the literature to assess the hemodynamics and myocardial functions in heart and become increasingly important in cardiovascular research [3-13]. Cardiac tissue is generally modeled as a hyper-elastic material [14]. Heart models can be divided into passive and active models to model the myocardial behavior [8, 15-23]. The incompressible elastic solids are generally used to model soft tissue in passive models. The exponential strain-energy functions have been widely used to describe the mechanical behavior of passive myocardium [15, 18]. The Holzapfel-type energy functions were commonly used for passive tissue stress $[9,24-26]$. Electrical activation is one way to trigger the cardiac active contraction $[8,16,17,19-21]$. While this method offers much more insight into the physiological processes, it also requires patient-specific identification of all the parameters inside the electromechanical models. In our case, the left ventricle $(\mathrm{LV})$ is a severely pathological $\mathrm{LV}$ which may differ considerably from the ones reported in literature for healthy patients. Applying time-dependent material properties in a solid model is also a method to model the active contraction [22, 27]. However, patient-specific time-dependent material properties were not able to be measured at the in vivo state due to current technological limitations. In our study, we applied an external force to implement the LV myocardial active contraction. The 3D active FSI models were applied to investigate the biomechanics of the myocardium and the intraventricular flow in LV [28]. However, it takes a lot of effort to obtain the proper external force boundary conditions to match the numerical simulation results with clinical data, which prevents the active computational models from time-sensitive clinical applications. Comparing to the active model, the pressure boundary conditions of passive models were easier to obtain. Additionally, it's easier to obtain the convergent solutions of passive model. In this study, we constructed 12 patient-specific computed-tomography (CT)-based passive FSI models for the LV of patients with HOCM, and we compared the numerical simulation results between these passive models and their corresponding active FSI models to investigate the differences.

\section{Results}

Based on 6 patients' pre-operative and post-operative LV CT Images, 12 patient-specific active and corresponding passive FSI models were constructed in this study. Figure 1 presents the numerical simulation results of stress- $\mathrm{P}_{1}$ on the cutting surface, $3 \mathrm{D}$ velocity 


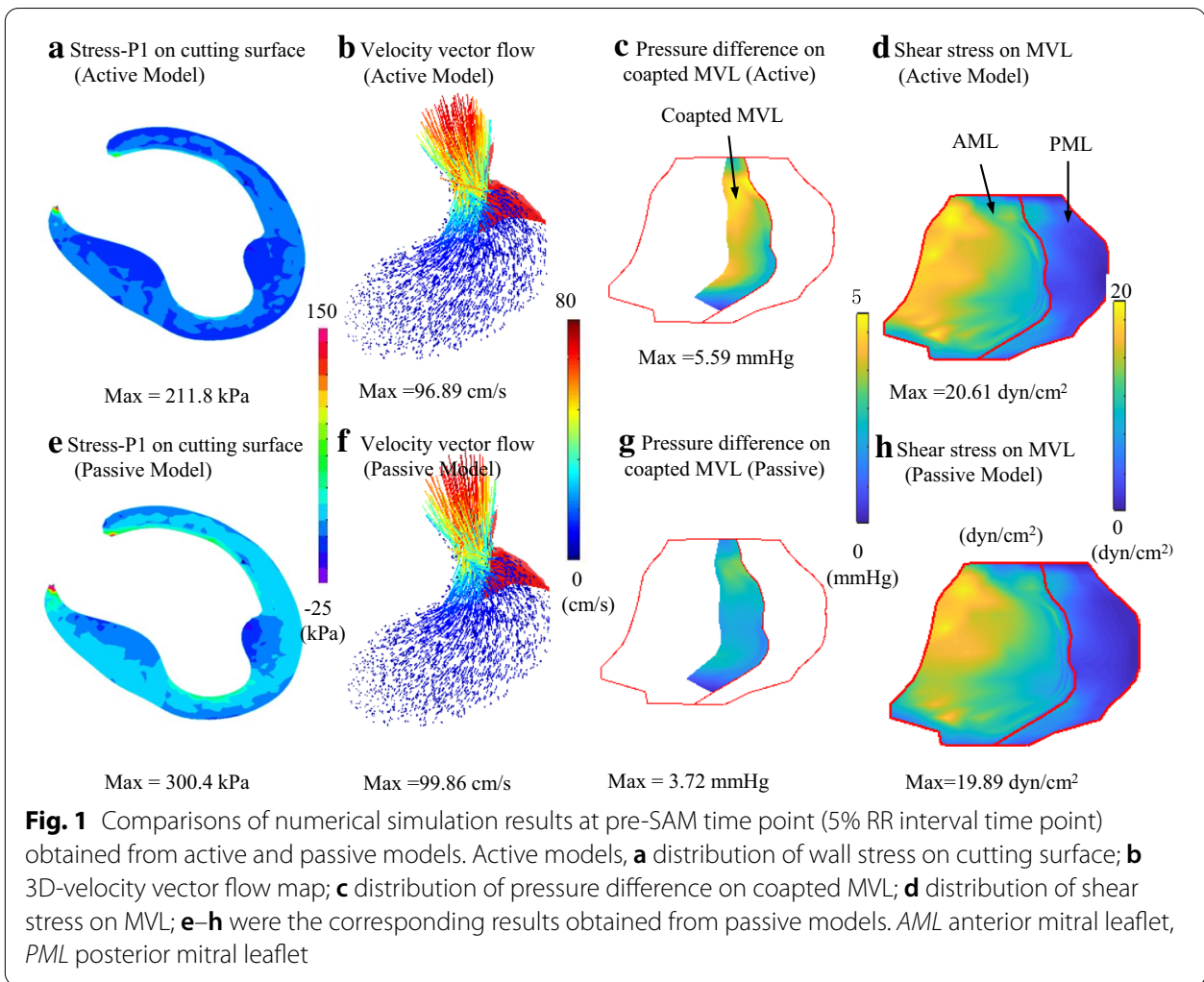

vector flow map, pressure difference, and shear stress distribution on the MVL at PreSAM time point obtained from pre-operative active and passive FSI models (patient 1). Figure 1 shows that the maximum stress value on the cutting surface obtained from passive models were $41.8 \%$ higher than that from active models, while the differences between fluid results were not significant. Details of the model comparisons are given below.

\section{Maximum wall stress values in passive models were $29.09 \%$ higher than those in active model}

Figure 2 presents the boxplots for the wall stress values obtained from slices in pre-operative and post-operative active and passive models. The mean values of maximum wall stress of each active model were higher than those obtained from corresponding passive model (Fig. 2).

The maximum/minimum/mean values of wall stress and wall strain of each patient obtained from active models were compared with those from passive models. The comparison results are presented in Table 1 . The mean value of maximum wall stress values in passive models were found $29.09 \%$ higher than that in active models $(122.7 \pm 38.1 \mathrm{kPa}$ vs. $95.0 \pm 26.9 \mathrm{kPa}, p=0.04)$. No significant difference was found in maximum wall strain values between passive and active models $(0.106 \pm 0.015$ vs. $0.112 \pm 0.019, p=0.39)$. 


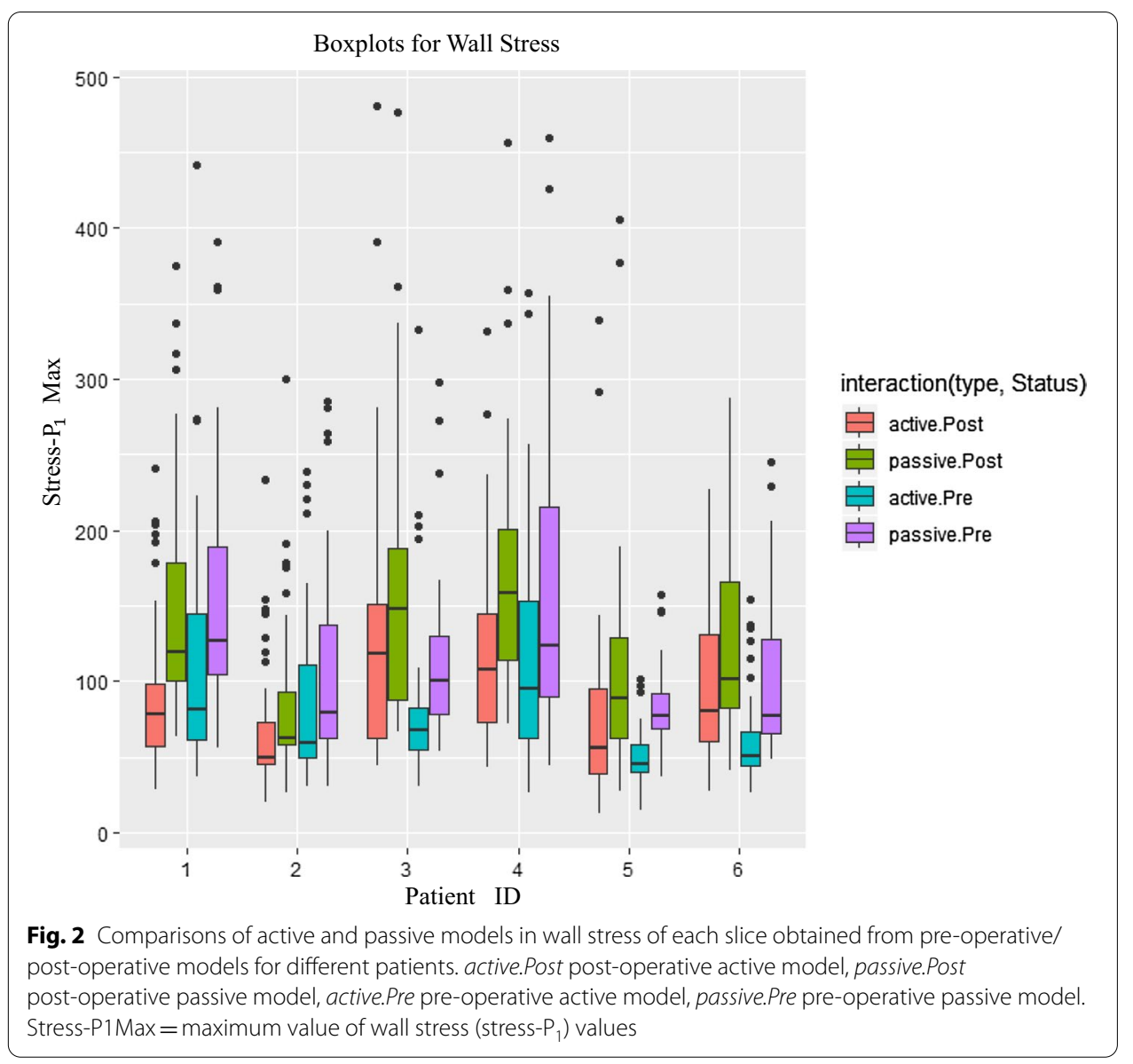

Table 1 Summary of comparisons of wall stress and strain values obtained from active and passive models

\begin{tabular}{lcccr}
\hline & Active $($ mean \pm SD) & Passive $($ mean \pm SD) & p value & Diff (\%) \\
\hline Max stress $-P_{1}(\mathrm{kPa})$ & $95.0 \pm 26.9$ & $122.7 \pm 38.1$ & 0.04 & 29.09 \\
Min stress- $P_{1}(\mathrm{kPa})$ & $-33.4 \pm 5.1$ & $-34.5 \pm 6.6$ & 0.65 & 3.27 \\
Mean stress- $P_{1}(\mathrm{kPa})$ & $2.7 \pm 2.8$ & $8.0 \pm 6.0$ & 0.01 & 194.85 \\
Max strain- $\mathrm{P}_{1}$ & $0.106 \pm 0.015$ & $0.112 \pm 0.019$ & 0.39 & 5.73 \\
Min strain- $P_{1}$ & $0.009 \pm 0.002$ & $0.009 \pm 0.001$ & 0.50 & -5.01 \\
Mean strain- $P_{1}$ & $0.046 \pm 0.009$ & $0.046 \pm 0.08$ & 0.91 & 0.86 \\
\hline
\end{tabular}

Diff (\%) represents the relative percentage difference based on active models

\section{No significant differences were found in fluid results}

No significant differences between active and passive models were found in mean values of maximum pressure values and shear stress on MVL (pressure: $82.3 \pm 11.7 \mathrm{kPa}$ vs. $83.3 \pm 12.0 \mathrm{kPa}, p=0.82$; shear stress: $12.1 \pm 6.8 \mathrm{dyn} / \mathrm{cm}^{2}$ vs. $\left.11.6 \pm 6.4 \mathrm{dyn} / \mathrm{cm}^{2}, p=0.85\right)$. The details of comparisons results of mean pressure and shear stress values are also listed in Table 2. 
Table 2 Summary of comparisons of pressure and fluid shear stress (FSS) results on mitral valve leaflet between active and passive models

\begin{tabular}{llllc}
\hline & Active $($ mean $\mathbf{S D})$ & Passive $($ mean $\mathbf{S D})$ & $\boldsymbol{p}$ value & Diff $(\%)$ \\
\hline Max pressure $(\mathrm{mmHg})$ & $82.3 \pm 11.7$ & $83.3 \pm 12.0$ & 0.82 & 1.32 \\
Min pressure $(\mathrm{mmHg})$ & $77.3 \pm 11.0$ & $80.8 \pm 11.1$ & 0.44 & 4.65 \\
Mean pressure $(\mathrm{mmHg})$ & $80.7 \pm 11.5$ & $82.6 \pm 11.8$ & 0.70 & 2.33 \\
Max FSS $\left(\mathrm{dyn} / \mathrm{cm}^{2}\right)$ & $12.1 \pm 6.8$ & $11.6 \pm 6.4$ & 0.85 & -3.82 \\
Min FSS $\left(\mathrm{dyn} / \mathrm{cm}^{2}\right)$ & $1.1 \pm 0.3$ & $0.8 \pm 0.3$ & 0.03 & -26.61 \\
Mean FSS $\left(\mathrm{dyn} / \mathrm{cm}^{2}\right)$ & $5.0 \pm 2.2$ & $4.8 \pm 1.9$ & 0.55 & -7.53 \\
\hline
\end{tabular}

Diff (\%) represents the relative percentage difference based on active models

Table 3 Summary of comparisons of pre-operative and post-operative differences of maximum/mean pressure values on coapted mitral valve leaflets (MVL) and shear stress on MVL in satisfactory-outcome group (group $1, n=5$ ) and unsatisfactory-outcome group (group 2, $n=1$ ) obtained from active and passive models

\begin{tabular}{|c|c|c|c|c|}
\hline & \multicolumn{2}{|c|}{ Active (pre-op vs. post- op) } & \multicolumn{2}{|c|}{ Passive (pre-op vs. post- op) } \\
\hline & Group $1($ mean \pm SD) & Group 2 & Group $1($ mean $\pm S D)$ & Group 2 \\
\hline \multicolumn{5}{|c|}{ Pressure difference $(\mathrm{mmHg})$} \\
\hline Max & $4.30 \pm 1.88$ vs. $0.57 \pm 0.36$ & 6.65 vs. 4.39 & $2.44 \pm 1.30$ vs. $0.68 \pm 0.29$ & 4.05 vs. 2.70 \\
\hline Mean & $2.22 \pm 1.03$ vs. $0.36 \pm 0.16$ & 3.05 vs. 2.02 & $1.17 \pm 0.68$ vs. $0.24 \pm 0.14$ & 1.79 vs. 1.19 \\
\hline \multicolumn{5}{|c|}{ Shear stress $\left(\mathrm{dyn} / \mathrm{cm}^{2}\right)$} \\
\hline Max & $21.5 \pm 4.8$ vs. $10.3 \pm 3.1$ & 34.6 vs. 37 & $18.8 \pm 2.1$ vs. $9.5 \pm 3.0$ & 33.5 vs. 35.8 \\
\hline Mean & $6.4 \pm 1.8$ vs. $3.3 \pm 1.3$ & 7.5 vs. 6.7 & $5.9 \pm 1.4$ vs. $3.1 \pm 1.2$ & 6.9 vs. 6.3 \\
\hline
\end{tabular}

Pressure difference and shear stress on MVL were found significantly decreased

after successful surgery in both of active and passive models

It was noticed that, before the surgery, the pressure on the posterior surface of MVL was higher than that on the anterior surface [28]. Therefore, to better investigate the differences between active and passive models, the pressure difference between posterior and anterior surfaces of MVL of the patients before and after surgery between different groups (patients receiving successful surgery vs. failed surgery) were investigated (Table 3). It was found that the pressure difference on MVL obtained from passive model decreased significantly after septal myectomy in satisfactory-outcome group (maximum pressure difference, $2.44 \pm 1.30 \mathrm{mmHg}$ vs. $0.68 \pm 0.29 \mathrm{mmHg}, p=0.017$; mean pressure difference, $1.17 \pm 0.68 \mathrm{mmHg}$ vs. $0.24 \pm 0.14 \mathrm{mmHg}, p=0.024)$.

Although the values of pressure differences between posterior and anterior surfaces of MVL in passive models were lower than those obtained from active models, the same observations were found from both models (Fig. 3).

The pre-operative and post-operative shear stress on MVL obtained from active and passive models were also investigated (Fig. 4). It was observed that the max shear stress on MVL decreased $52.1 \%(p=0.01)$ in active models and $49.5 \%(p=0.004)$ in passive models after successful surgical septal myectomy. The mean shear stress was found decreased significantly in both of active models (pre-op: $6.38 \pm 1.76 \mathrm{dyn} / \mathrm{cm}^{2}$ vs. postop: $3.27 \pm 1.30 \mathrm{dyn} / \mathrm{cm}^{2}, p=0.004$ ) and passive models (pre-op: $5.85 \pm 1.41 \mathrm{dyn} / \mathrm{cm}^{2} \mathrm{vs}$. post-op: $3.07 \pm 1.22 \mathrm{dyn} / \mathrm{cm}^{2}, p=0.004$ ) (Table 3 ). The post-operative maximum shear 
a Results obtained from active models
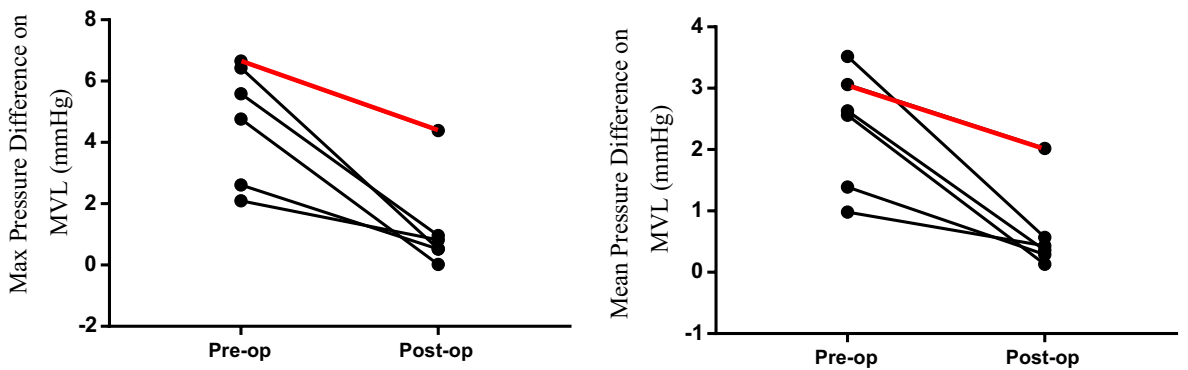

b Results obtained from passive models
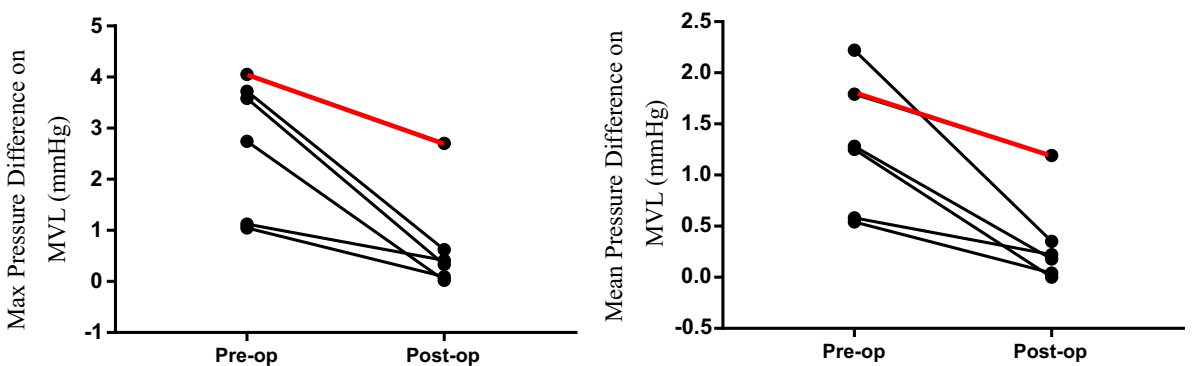

Fig. 3 Comparisons of the difference of maximum/mean pressure values on coapted mitral valve leaflets (MVL) before (pre-op) and after surgery (post-op). The red lines indicate the patient received an unsatisfactory outcome, and the black lines indicate that the patients receiving successful surgery. a Results obtained from active models; $\mathbf{b}$ results obtained from passive models
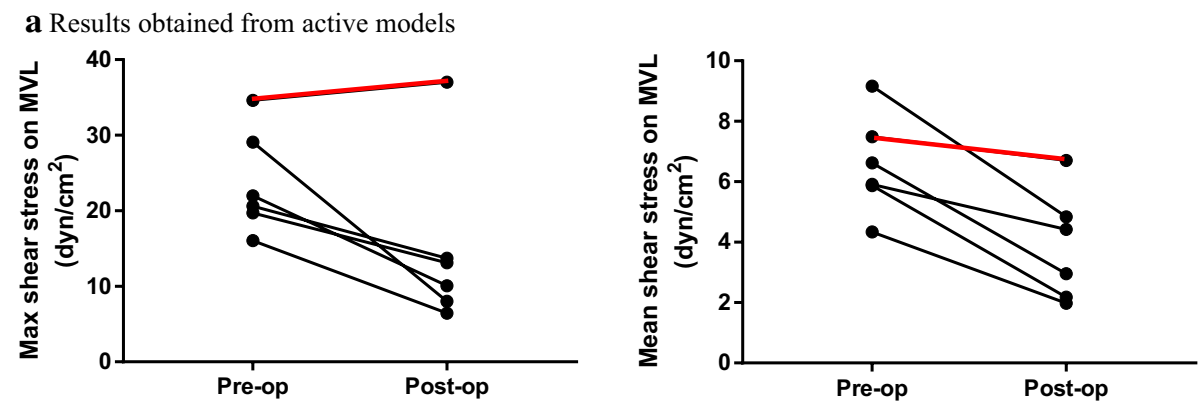

b Results obtained from passive models
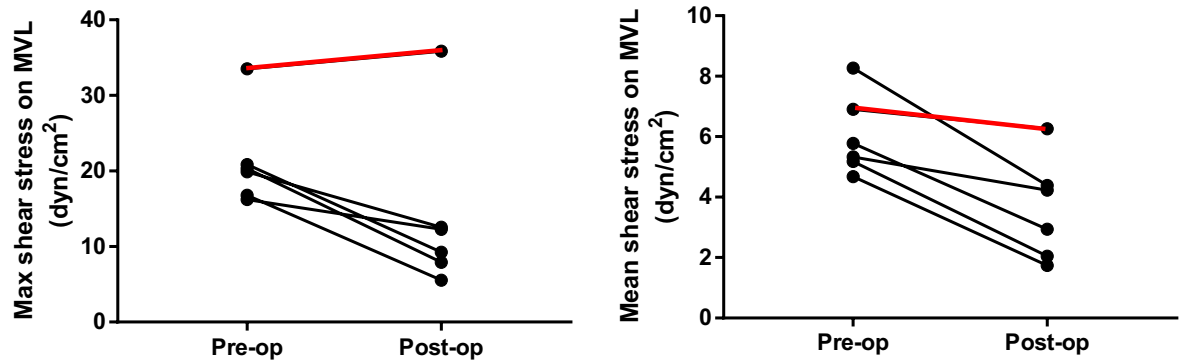

Fig. 4 Comparisons of the mean value of maximum/mean fluid shear stress on coapted mitral valve leaflets (MVL) before and after surgery. The black lines indicate the patients with successful surgery, and the red lines indicate the patient with failed surgery. $\mathbf{a}$ Results obtained from active models; $\mathbf{b}$ results obtained from passive models 
stress on MVL for the patient receiving failed surgery were 259\% (active models, 37.0 dyn $/ \mathrm{cm}^{2}$ vs. $10.3 \mathrm{dyn} / \mathrm{cm}^{2}$ ) and $277 \%$ (passive models, $35.8 \mathrm{dyn} / \mathrm{cm}^{2}$ vs. $9.5 \mathrm{dyn} / \mathrm{cm}^{2}$ ) higher than the mean value of those in group 1 (Table 3 ).

\section{Discussion}

In this study, there were 12 active and corresponding passive FSI models constructed to compare the differences of simulation results between these two types of models. The numerical simulation results at pre-SAM time point, including wall stress and strain on the inner boundary of LV, and pressure and shear stress on MVL, were extracted to be compared. It was found that there was a significant difference in wall stress between the passive and active models. The mean value of maximum wall stress in passive models was $29.09 \%$ higher than that in active model. However, there were no significant differences of strain values and fluid results between the active and passive models. Based on simulation results obtained from passive models, the pressure difference on coapted MVL and shear stress on MVL were found decreased significantly after successful surgery, but remained still high after failed surgery. These findings are in good agreement with the results obtained from active models [28].

While the mechanisms driving the left ventricle motion in the passive model are different from real heart motion, the simulation of the hemodynamic status, the motion and deformation of LV can still be approached by the passive models. In both of our passive and active models, the boundary conditions were adjusted to match the simulation results with clinical data. That is, at pre-SAM time, the simulation results of average pressure, LV volume, and LVOT velocity were matched with clinical measured data well in both of passive and active models. Our results indicated that, if we focus on the simulation results of left ventricle at some specific time points, the passive model may provide simulation results of blood flow matching well with active models with proper boundary conditions and sufficient clinical data.

Table 4 presents the number of manually adjustments of simulation experiments for passive model and active models. The total number of numerical simulation experiments

Table 4 Summary of comparisons of the total number of numerical experiments for obtaining the proper boundary conditions between active models and passive models

\begin{tabular}{lll}
\hline Model & Passive & Active \\
\hline P1-pre & 7 & 14 \\
P1-post & 1 & 3 \\
P2-pre & 7 & 24 \\
P2-post & 4 & 12 \\
P3-pre & 6 & 13 \\
P3-post & 4 & 15 \\
P4-pre & 5 & 28 \\
P4-post & 5 & 13 \\
P5-pre & 7 & 25 \\
P5-post & 5 & 14 \\
P6-pre & 5 & 17 \\
P6-post & 6 & 12 \\
Mean \pm sd & $5.2 \pm 1.6$ & $15.8 \pm 6.6$ \\
\hline
\end{tabular}


for active model to receive the proper boundary conditions was about two times more than that of passive models ( $15.8 \pm 6.6$ vs. $5.2 \pm 1.6)$. Every simulation experiment takes around $3 \mathrm{~h}$. Therefore, for each FSI model, it took at least more than $30 \mathrm{~h}$ to obtain the proper boundary conditions for active models comparing to passive models. Suppose the researcher works $6 \mathrm{~h} /$ day, 5 weekday/week. Which means the patient needs around one more week to receive the simulation results and surgical plan. In addition, to obtain the convergent solutions, for every simulations, the active models needs $85 \%$ more iteration times than passive models (active vs. passive, $12.3 \pm 3.3$ vs. $6.7 \pm 0.7$ ). The passive models also decrease the difficulty of convergence significantly. Since the goal of our study was to perform hemodynamic analysis of LV to investigate the mechanisms of SAM, and the passive models provided good approximated hemodynamic simulations, the passive models may be used as a good substitution model to active models to investigate the initiation of SAM.

Some limitations of this study are acknowledged here. The main limitation of the study is the small sample size which results in limited statistical power. The reason for the small sample size is that the computational modeling method takes large time costs, (1) it takes a lot of effort to find the proper boundary conditions for active models; (2) the construction procedure for both of active and passive models also takes time; (3) it is not easy to obtain patient-specific CT data, especially for the follow up CT data. Currently, multi-patient studies for heart model simulations is still rare. Adding more patients will be our future effort. Applying commercial software, such as HyperMesh, to automatically create the finite element mesh to save the construction time will be considered. Although CT images provided high-resolution medical images, the chordae tendineae is still impossible to be displayed. Therefore, the chordae tendineae is not included in our model. Due to rapid motion, our technique also restricts us from simulating mitral valve dynamic motions. From the end of the isovolumic systole to the pre-SAM time point, the mitral valve is almost closed, therefore, this simplification would have little impact on fluid results for analyzing the mechanisms of initiation of SAM. It should also be noted that, the fibre orientation plays a critical role both in passive inflation $[26,29,30]$ and active contraction [31,32]. The anisotropic models may improve the computational prediction accuracies. However, in the heart in HCM patients, the alignment of muscle cells or myocardial disarray was found very irregular and disorganized [33, 34]. The fiber orientation data were not able to be obtained with current technology. Therefore, we assumed that the material of the left ventricle was isotropic. In the future, the single or multi-layer anisotropic models would be introduced into our model to investigate other patients' left ventricle models.

\section{Conclusion}

In this study, based on CT images of 6 HOCM patients before and after surgical septal myectomy, 12 active and corresponding passive FSI models were developed to compare the simulated biomechanics and hemodynamics behaviors between passive and active models. It was found that, between these models, there was a significant difference in wall stress, but the differences in hemodynamic simulation results were not significant. Compared with active models, the passive models decrease the complexity of the modeling construction and the difficulty of convergence significantly. Therefore, with proper 
boundary condition, the passive model may be a good approximation to active model with less computational cost to perform hemodynamic analysis for left ventricle to investigate the initiation of SAM. Prospective and large-scale studies are needed to further validate our findings.

\section{Methods}

\section{Data acquisition}

Institution review board approval on human subject research at Fuwai Hospital was obtained for this study. For model constructions and analysis, the CT images before and after surgery were obtained from six patients with HOCM who received septal myectomy in Fuwai Hospital. All these six patients had severe systolic anterior motion (SAM) before surgery. Based on the outcomes of surgery, patients were categorized into two groups, satisfactory-outcome group (patient no. 1-5) which successfully eliminated SAM and mitral regurgitation, and unsatisfactory-outcome group (patient no. 6) which had residual SAM and mitral regurgitation after surgery. Pre-operative and post-operative echocardiographic characteristics are summarized in Table 5.

Cardiac CT images were obtained at every $5 \%$ inter-beat (RR) interval. In all these six patients, the beginning time of SAM ranged from 5 to $8 \%$ RR interval in the cardiac cycle. Therefore, to investigate the initiation of SAM, the pre-operative and post-operative CT images at 5\% RR interval were selected as pre-SAM time point data to construct the computational models. The field of view was $256 \mathrm{~mm} \times 256 \mathrm{~mm}$, the matrix was $512 \times 512$, and the slice thickness was $0.625 \mathrm{~mm}$. The original slice thickness of the CT images was $0.625 \mathrm{~mm}$, and there were about $110-150$ slices of images covering the LV. The segmentation was performed manually by Dr. Deng to obtain digital contours of each component for modeling constructions. The segmentation results were all examined by experienced radiologist. Volume component-fitting method was employed to generate meshes for left ventricle with irregular geometry. Using this technique, both the left ventricle and fluid domains were divided into thousands of small "volumes" to curve-fit the geometry. The edge of each volume will be further divided into several divisions to generate the final mesh in ADINA (ADINA R\&D, Watertown, MA). By applying this method, the mesh generated would not be too distorted under large deformation. More details about the CT images and segmentation for the construction of FSI models can be found from Deng et al. [28, 35]. Patients' heart rate and blood pressure at the time of CT examinations were used in the simulation. The patient-specific LV volume, pressure and the left ventricular outflow tract (LVOT) velocity at pre-SAM time obtained from echo and MRI data were used to verify the simulation results (Table 6).

\section{Solid models}

The modified non-linear Mooney-Rivlin model was adopted to characterize the mechanical behavior of LV myocardium. The strain-energy function for the isotopic incompressible Mooney-Rivlin model was expressed as,

$$
W=c_{1}\left(I_{1}-3\right)+c_{2}\left(I_{2}-3\right)+D_{1}\left[\mathrm{e}^{D_{2}\left(I_{1}-3\right)}-1\right]
$$

where $I_{1}$, and $I_{2}$ are the first and second strain invariants, 


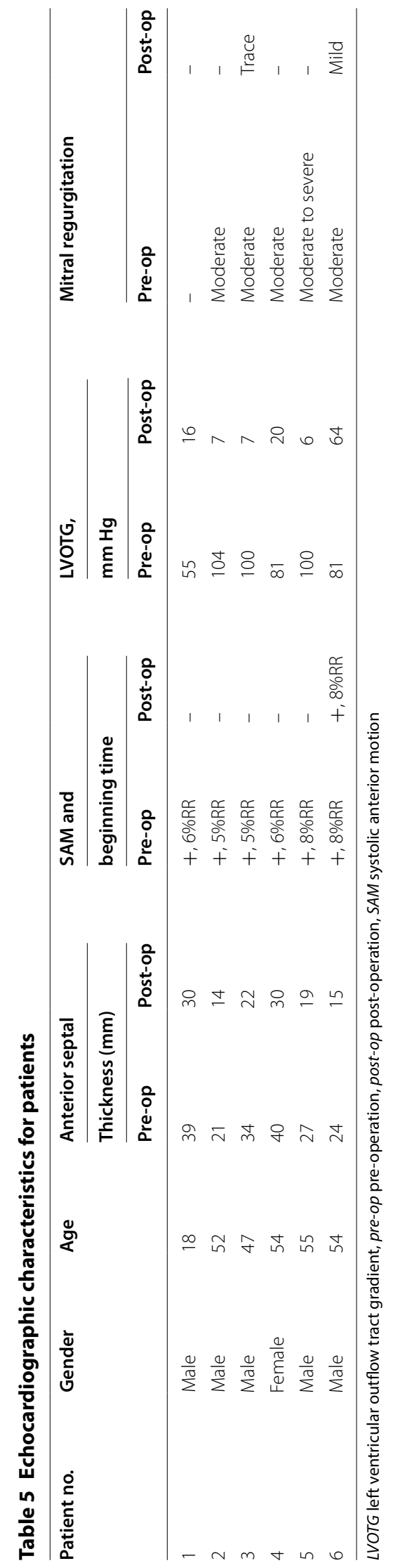


Table 6 Summary of the comparisons of simulation results of LV pressure, volume, and the left ventricle outflow tract (LVOT) velocity at pre-SAM time obtained from active (Act) and passive (Pas) models, and those from clinical data

\begin{tabular}{|c|c|c|c|c|c|c|c|c|c|}
\hline \multirow[t]{3}{*}{ Patient no. } & \multicolumn{3}{|c|}{ LV pressure $(\mathrm{mm} \mathrm{Hg})$} & \multicolumn{3}{|c|}{ LV volume (ml) } & \multicolumn{3}{|c|}{ LVOT velocity $(\mathrm{m} / \mathrm{s})$} \\
\hline & \multirow[t]{2}{*}{ Clinical data } & \multicolumn{2}{|c|}{$\begin{array}{l}\text { Simulation } \\
\text { results }\end{array}$} & \multirow[t]{2}{*}{ Clinical data } & \multicolumn{2}{|c|}{$\begin{array}{l}\text { Simulation } \\
\text { results }\end{array}$} & \multirow[t]{2}{*}{ Clinical data } & \multicolumn{2}{|c|}{$\begin{array}{l}\text { Simulation } \\
\text { results }\end{array}$} \\
\hline & & Act & Pas & & Act & Pas & & Act & Pas \\
\hline 1 & 67 & 65.9 & 68.3 & 136.7 & 137 & 137 & 0.56 & 0.57 & 0.57 \\
\hline 2 & 85 & 85.2 & 87.9 & 128.6 & 128 & 129 & 1.00 & 0.97 & 0.99 \\
\hline 3 & 85 & 85.5 & 87.1 & 126.5 & 125 & 127 & 0.83 & 0.79 & 0.83 \\
\hline 4 & 75 & 73.7 & 80.5 & 146.4 & 147 & 147 & 1.20 & 1.19 & 1.20 \\
\hline 5 & 72 & 72.2 & 76.0 & 191.5 & 191 & 192 & 1.10 & 1.11 & 1.10 \\
\hline 6 & 93 & 90.7 & 99.5 & 106.5 & 106 & 107 & 1.36 & 1.35 & 1.32 \\
\hline
\end{tabular}

$$
I_{1}=\sum C_{i i}, I_{2}=\frac{1}{2}\left(I_{1}^{2}-C_{i j} C_{i j}\right)
$$

$\boldsymbol{C}=\left[C_{i j}\right]=\boldsymbol{X}^{\mathrm{T}} \boldsymbol{X}$ is the right Cauchy-Green deformation tensor, $\boldsymbol{X}=\left[X_{i j}\right]=\left[\partial x_{i} / \partial a_{j}\right]$, where $x_{i}$ is the current position, $a_{j}$ is the original position, and $c_{1}, c_{2}, D_{1}$, and $D_{2}$ are material constants $[27,36]$. Details of the determination of the patient-specific material constants have been described in our previous publication $[28,35]$.

\section{Fluid dynamics simulation}

The blood in the LV was treated as a laminar, Newtonian, viscous and an incompressible fluid. In this study, we set the viscosity of $\mu=0.04 \mathrm{dyncm}^{-2}$ and density of $\rho=1 \mathrm{gcm}^{-3}$ for blood properties. The Navier-Stokes equation with Arbitrary Lagrangian Eulerian formula was used as the governing equation. Boundary conditions in the simulation were set such that, during the ejection phase, when blood was ejected out of the left ventricle, the outlet (aortic valve) kept open and the inlet (mitral valve) was closed (flow velocity was set to zero, and the pressure was left unspecified). A no-slip boundary condition between the interfaces was assumed. The structure and fluid models were coupled through their interfaces [6, 27, 36]. The complete fluid model is given by,

$$
\begin{aligned}
& \rho\left(\partial \boldsymbol{u} / \partial t+\left(\left(\boldsymbol{u}-\boldsymbol{u}_{g}\right) \bullet \nabla\right) \boldsymbol{u}\right)=\nabla p+\mu \nabla^{2} \boldsymbol{u} \\
& \nabla \bullet \boldsymbol{u}=0 \\
& \left.\boldsymbol{u}\right|_{\Gamma}=\frac{\partial \boldsymbol{x}}{\partial \mathrm{t}},\left.\frac{\partial \mathbf{v}}{\partial n}\right|_{\text {inlet,outlet }}=0 \\
& \left.p\right|_{\text {valve }}=p_{\text {inlet }}(t),\left.\boldsymbol{u}\right|_{\text {aorta }}=0 \text { (fillingphase) } \\
& \left.p\right|_{\text {aorta }}=p_{\text {outlet }}(t),\left.\boldsymbol{u}\right|_{\text {valve }}=0 \text { (ejectionphase) }
\end{aligned}
$$




$$
\left.\sigma_{i j}^{f} n_{j}^{f}\right|_{\text {interface }}=\left.\sigma_{i j}^{s} n_{j}^{s}\right|_{\text {interface }}
$$

where $\boldsymbol{u}$ and $p$ are fluid velocity and pressure, $\boldsymbol{u}_{g}$ is mesh velocity, $\Gamma$ stands for the left ventricle inner wall, $\sigma$ is structure stress tensor, (superscripts, $f$ and $s$, indicate blood and the left ventricle, respectively), and $\boldsymbol{n}$ is the outward normal directions. The governing equations of (Eqs. (3-4)) would be rewritten to weak form by using Galerkin method [36]. Then, interpolation functions would be introduced for each element, and finite element governing equations are expressed in terms of interpolation functions. Difference method and Newton-Raphson iteration method were also used to obtain the solution iteratively.

\section{Solution method}

In the construction process of both of active and passive models, the initial shrinkage rate was set as $5 \%$ to receive the zero-load geometry which is the starting geometry for the numerical simulation [37, 38]. When the pressure was applied at inlet, the left ventricle expanded in short-axis and long-axis direction, and then regained its in vivo morphology. During this phase, the mitral valve (MV) kept open and the blood filled into LV though MV. At the end of this phase, LV reaches its maximum volume and the pressure in LV increases to end of isovolumic systole pressure. The information of the blood flow and mechanics of LV were received as the starting state of the simulation for the phase from end of systole phase to pre-SAM time point. The details of the pre-shrink process can be found from our previously published paper $[28,35]$.

The finite element meshes was generated by the volume component-fitting method $[6,27]$. The constructed computational models were solved by commercial software ADINA (ADINA R\&D, Watertown, MA), which uses the Newton-Raphson iteration and unstructured finite elements method. The iterative FSI coupling solution method, which requires less memory than the Direct FSI Coupling method, was applied to handle fluid-structure interaction. At each time step, the fluid and solid equations will be solved individually where the latest information provided by the other part is used as boundary conditions at each time step. Specifically speaking, the solid model firstly will be solved with the latest pressure and stress condition provided by the flow part of the last time step. Then, the fluid model will be solved by using the displacement and velocity obtained from the structure part as the boundary conditions. These two steps will be repeated until the convergence is reached. Mesh analysis was performed for each model by reducing the mesh density in each dimension by $10 \%$ until differences between solutions from two consecutive meshes were negligible (less than 1\% in L2-norm). The optimal element size in each dimension is between 0.05 and $0.1 \mathrm{~cm}$. For each patient, there were around 90,000 elements and 60,000 elements for the solid and fluid model, respectively.

\section{Differences between the passive and active models}

The simulations of the phase from end of systole phase to pre-SAM time point between active model and passive model were different. In passive models, the left ventricle muscle was deflated by the patient-specific pressure condition which was scaled based on measured blood pressure conditions, and the pressure difference between LV and aorta 
which was obtained from ultrasound scanning. In active models, we simulated the LV active contraction by specifying the external forces on epicardium, and the pressure condition at outlet (aortic valve) from the end of isovolumic systole phase to pre-SAM time point (5\% RR) [28]. Based on the clinical measured data of LV volume, LV pressure, and LVOT velocity obtained from echo and MRI data at the end of isovolumic systole phase and pre-SAM time point, the external forces were applied on each element of the epicardium, and the pressure condition at outlet at each time step were numerically interpolated. The boundary conditions were manually adjusted accordingly, such that the difference between clinical measured data and the simulation results were less than $5 \%$. The real LV active contraction motion was then implemented. The adjustment of the boundary conditions was primarily based on the comparisons of numerical results and clinical data at each time step. For more details about the construction of active and passive models, we refer the reader to our previous publications [28].

\section{Data extraction and statistical analysis}

The stress, strain, and shear stress are all tensors, therefore, the maximum principal stress (stress- $\left.\mathrm{P}_{1}\right)$, maximum principal strain ( strain- $\mathrm{P}_{1}$ ), and maximum shear stress at each node were chosen as wall stress, strain, and shear stress, respectively, for convenience. Data for wall stress and wall strain of all integral nodes on the inner boundary of left ventricle (endocardium) and fluid shear stress and pressure of all integral nodes on mitral valve were extracted from 3D FSI solutions. For each slice, the maximum/mean/ minimum values of the simulation results of wall stress, wall strain, fluid shear stress, and pressure were selected for analysis. Which means, there were at least 20 samples come from the same patient (but comes from different slice). The data were in non-independent data structure. Therefore, the linear mixed-effect-model $[39,40]$ was used to compare the simulation results between passive and active models. The statistical significance was established at a $p$ value of $<0.05$. All statistical analyses in this study were conducted using R software (version 3.5.1).

\section{Abbreviations}

FSI: Fluid-structure interactions; MVL: Mitral valve leaflet; SAM: Systolic anterior motion; HOCM: Hypertrophic obstructive cardiomyopathy; LV: Left ventricle; CT: Computed-tomography; RR: Inter-beat; LVOT: Left ventricular outflow tract; MV: Mitral valve; Stress- $\mathrm{P}_{1}$ : Maximum principal stress; Strain- $\mathrm{P}_{1}$ : Maximum principal strain.

\section{Acknowledgements}

The authors thank Xinshuang Ren for collecting the CT data. Bin Lyu performed the cardiac CT test. Fujian Duan performed the echocardiography.

\section{Author contributions}

XH and LD designed the study. YS performed the operations. LD collected the clinical data. CY constructed the computational model and performed the numerical simulation. LD and XH wrote the paper. $\mathrm{HZ}, \mathrm{ML}$, and XH perform the statistical analysis. YS, ML, and DT critically reviewed the paper. All authors read and approved the final manuscript.

\section{Funding}

The research for this project is funded in part by the Natural Science Foundation of Fujian Province of China Grant 2017J01009, the Fundamental Research Funds for the Central Universities Grant 20720180004, the National Natural Sciences Foundation of China Grants 11672001, 82000472, 11671335, and 11972117, and the NIH/NHLBI R01 HL089269 (Dr. Tang).

Availability of data and materials

The datasets generated during and/or analyzed during the current study are available from the corresponding author at reasonable request.

Ethics approval and consent to participate

This study was approved by Institution review board approval on human subject research at Fuwai Hospital. 


\section{Consent for publication}

Not applicable.

\section{Competing interests}

The authors declare that they have no competing interests.

\section{Author details}

${ }^{1}$ School of Mathematical Sciences, Xiamen University, Xiamen 361005, Fujian, China. ${ }^{2}$ Mathematical Sciences Department, Worcester Polytechnic Institute, Worcester, MA 01609, USA. ${ }^{3}$ Department of Cardiac Surgery, Fuwai Hospital, Chinese Academy of Medical Sciences, Beijing, China. ${ }^{4}$ School of Mathematical Sciences, Sichuan Normal University, Chengdu, Sichuan, China. ${ }^{5}$ Network Technology Research Institute, China United Network Communications Co., Ltd. Beijing, China. ${ }^{6}$ Department of Mathematics and Statistics, University of Victoria, Victoria, BC V8P 5C2, Canada. ${ }^{7}$ School of Biological Science and Medical Engineering, Southeast University, Nanjing, China.

Received: 6 August 2020 Accepted: 10 December 2020

Published online: 12 January 2021

\section{References}

1. McCully RB, Nishimura RA, Tajik AJ, Schaff HV, Danielson GKJC. Extent of clinical improvement after surgical treatment of hypertrophic obstructive cardiomyopathy. Circulation. 1996;94(3):467-71.

2. Maron BJ, Maron MS. The 20 advances that have defined contemporary hypertrophic cardiomyopathy. Trends Cardiovasc Med. 2015;25(1):54-64.

3. Hunter PJ, Pullan AJ, Smaill BH. Modeling total heart function. Annu Rev Biomed Eng. 2003;5:147-77.

4. McCulloch A, Waldman L, Rogers J, Guccione J. Large-scale finite element analysis of the beating heart. Crit Rev Biomed Eng. 1992;20(5-6):427-49.

5. Sun W, Martin C, Pham T. Computational modeling of cardiac valve function and intervention. Annu Rev Biomed Eng. 2014;16:53-76.

6. Tang D, Yang C, Geva T, Del Nido PJ. Patient-specific MRI-based 3D FSI RV/LV/patch models for pulmonary valve replacement surgery and patch optimization. J Biomech Eng. 2008;130(4):041010.

7. Krishnamurthy A, Villongco CT, Chuang J, Frank LR, Nigam V, Belezzuoli E, Stark P, Krummen DE, Narayan S, Omens JH, et al. Patient-specific models of cardiac biomechanics. J Comput Phys. 2013;244:4-21.

8. Baillargeon B, Rebelo N, Fox DD, Taylor RL, Kuhl E. The Living Heart Project: a robust and integrative simulator for human heart function. Eur J Mech A Solids. 2014;48:38-47.

9. Palit A, Franciosa P, Bhudia SK, Arvanitis TN, Turley GA, Williams MA. Passive diastolic modelling of human ventricles: effects of base movement and geometrical heterogeneity. J Biomech. 2017;52:95-105.

10. Yin Z, Zhang W, Zhao D, Sulejmani F, Feng Y, Huo Y, Tan W. Cardiac wall mechanics analysis in hypertension-induced heart failure rats with preserved ejection fraction. J Biomech. 2020;98:109428.

11. Zhuan X, Luo X, Gao H, Ogden RW. Coupled agent-based and hyperelastic modelling of the left ventricle postmyocardial infarction. Int J Numer Method Biomed Eng. 2019;35(1):e3155.

12. Yu H, Del Nido PJ, Geva T, Yang C, Tang A, Wu Z, Rathod RH, Huang X, Billiar KL, Tang D. Patient-specific in vivo right ventricle material parameter estimation for patients with tetralogy of Fallot using MRI-based models with different zero-load diastole and systole morphologies. Int J Cardiol. 2019;276:93-9.

13. Yu H, Tang D, Geva T, Yang C, Wu Z, Rathod RH, Huang X, Billiar KL, Del Nido PJ. Ventricle stress/strain comparisons between tetralogy of Fallot patients and healthy using models with different zero-load diastole and systole morphologies. PLOS ONE. 2019;14(8):e0220328.

14. Göktepe S, Acharya S, Wong J, Kuhl E. Computational modeling of passive myocardium. Int J Numer Methods Biomed Eng. 2011;27(1):1-12.

15. Emery J, Omens J, McCulloch A. Biaxial mechanics of the passively overstretched left ventricle. Circ Physiol. 1997;272(5):H2299-305.

16. Gurev V, Constantino J, Rice J, Trayanova N. Distribution of electromechanical delay in the heart: insights from a three-dimensional electromechanical model. Biophys J. 2010;99(3):745-54.

17. Niederer SA, Smith NP. The role of the Frank-Starling law in the transduction of cellular work to whole organ pump function: a computational modeling analysis. PLoS Comput Biol. 2009;5(4):e1000371.

18. Omens $\mathrm{JH}$, Mackenna DA, McCulloch AD. Measurement of strain and analysis of stress in resting rat left ventricular myocardium. J Biomech. 1993;26(6):665-76.

19. Pfeiffer ER, Tangney JR, Omens JH, McCulloch AD. Biomechanics of cardiac electromechanical coupling and mechanoelectric feedback. J Biomech Eng. 2014;136(2):021007.

20. Rice JJ, Wang F, Bers DM, De Tombe PP. Approximate model of cooperative activation and crossbridge cycling in cardiac muscle using ordinary differential equations. Biophys J . 2008;95(5):2368-90.

21. Usyk TP, McCulloch AD. Relationship between regional shortening and asynchronous electrical activation in a threedimensional model of ventricular electromechanics. J Cardiovasc Electrophysiol. 2003;14:S196-202.

22. Yang C, Tang D, Geva T, Rathod R, Yamauchi H, Gooty V, Tang A, Gaudette G, Billiar KL, Kural MH. Using contracting band to improve right ventricle ejection fraction for patients with repaired tetralogy of Fallot: a modeling study using patient-specific CMR-based 2-layer anisotropic models of human right and left ventricles. J Thorac Cardiovasc Surg. 2013;145(1):285.e282-293.e282.

23. Avazmohammadi RSJ, Li DS, Raut SS, Gorman RC, Sacks MS. A Contemporary look at biomechanical models of myocardium. Annu Rev Biomed Eng. 2019;21:417-42.

24. Holzapfel GA, Ogden RW. Constitutive modelling of passive myocardium: a structurally based framework for material characterization. Philos Trans A Math Phys Eng Sci. 1902;2009(367):3445-75. 
25. Wang HM, Luo XY, Gao H, Ogden RW, Griffith BE, Berry C, Wang TJ. A modified Holzapfel-Ogden law for a residually stressed finite strain model of the human left ventricle in diastole. Biomech Model Mechanobiol. 2014;13(1):99-113.

26. Gao H, Li WG, Cai L, Berry C, Luo XY. Parameter estimation in a Holzapfel-Ogden law for healthy myocardium. J Eng Math. 2015;95(1):231-48.

27. Yang C, Tang D, Haber I, Geva T, Del Nido PJ. In vivo MRI-based 3D FSI RV/LV models for human right ventricle and patch design for potential computer-aided surgery optimization. Comput Struct. 2007;85(11-14):988-97.

28. Deng L, Huang X, Yang C, Lyu B, Duan F, Tang D, Song Y. Numerical simulation study on systolic anterior motion of the mitral valve in hypertrophic obstructive cardiomyopathy. Int J Cardiol. 2018;266:167-73.

29. Palit A, Bhudia SK, Arvanitis TN, Sherwood V, Wayte S, Turley GA, Williams MA. Effect of fibre orientation on diastolic mechanics of human ventricle. Annu Int Conf IEEE Eng Med Biol Soc. 2015;2015:6523-6.

30. Palit A, Bhudia SK, Arvanitis TN, Turley GA, Williams MA. In vivo estimation of passive biomechanical properties of human myocardium. Med Biol Eng Comput. 2018;56(9):1615-31.

31. Genet M, Lee LC, Nguyen R, Haraldsson H, Acevedo-Bolton G, Zhang Z, Ge L, Ordovas K, Kozerke S, Guccione JM. Distribution of normal human left ventricular myofiber stress at end diastole and end systole: a target for in silico design of heart failure treatments. J Appl Physiol (1985). 2014;117(2):142-52.

32. Lee LC, Ge L, Zhang Z, Pease M, Nikolic SD, Mishra R, Ratcliffe MB, Guccione JM. Patient-specific finite element modeling of the Cardiokinetix Parachute $\left({ }^{(}\right)$device: effects on left ventricular wall stress and function. Med Biol Eng Comput. 2014;52(6):557-66.

33. Davies MJ, McKenna WJ. Hypertrophic cardiomyopathy-pathology and pathogenesis. Histopathology. 1995;26(6):493-500

34. Davies MJ, McKenna WJ. Hypertrophic cardiomyopathy: an introduction to pathology and pathogenesis. Br Heart J. 1994;72(6 Suppl):S2-3.

35. Deng L, Huang X, Yang C, Song Y, Tang D. Patient-specific CT-based 3D passive FSI model for left ventricle in hypertrophic obstructive cardiomyopathy. Comput Methods Biomech Biomed Engin. 2018;21(3):255-63.

36. Bathe K. Theory and modeling guide. Watertown: ADINA R\&D, Inc; 2002.

37. Tang D, Del Nido PJ, Yang C, Zuo H, Huang X, Rathod RH, Gooty V, Tang A, Wu Z, Billiar KL, Geva T. Patient-specific MRI-based right ventricle models using different zero-load diastole and systole geometries for better cardiac stress and strain calculations and pulmonary valve replacement surgical outcome predictions. PLOS ONE. 2016;11(9):e0162986.

38. Tang D, Zuo H, Yang C, Wu Z, Huang X, Rathod RH, Tang A, Billiar KL, Geva T. Comparison of right ventricle morphological and mechanical characteristics for healthy and patients with tetralogy of Fallot: an in vivo MRI-based modeling study. Mol Cell Biomech. 2017;14(3):137-51.

39. Bates D, Mächler M, Bolker B, Walker S. Fitting linear mixed-effects models using Ime4. J Stat Softw. 2015;67:1-48.

40. Tang D, Yang C, Del Nido PJ, Zuo H, Rathod RH, Huang X, Gooty V, Tang A, Billiar KL, Wu Z, Geva T. Mechanical stress is associated with right ventricular response to pulmonary valve replacement in patients with repaired tetralogy of Fallot. J Thorac Cardiovasc Surg. 2016;151(3):687 e683-694 e683.

\section{Publisher's Note}

Springer Nature remains neutral with regard to jurisdictional claims in published maps and institutional affiliations.

- fast, convenient online submission

- thorough peer review by experienced researchers in your field

- rapid publication on acceptance

- support for research data, including large and complex data types

- gold Open Access which fosters wider collaboration and increased citations

- maximum visibility for your research: over $100 \mathrm{M}$ website views per year

At BMC, research is always in progress.

Learn more biomedcentral.com/submissions 